\title{
Decentralized Hydraulics for Micro Excavator
}

\author{
Shuzhong Zhang ${ }^{1,2}$, Tatiana Minav ${ }^{1}$, and Matti Pietola ${ }^{1}$ \\ 1. Department of Mechanical Engineering, Aalto University, Espoo, Finland \\ 2. School of Mechanical Engineering and Automotive, Fujian University of Technology, Fuzhou, China \\ E-mail: Shuzhong.Zhang@aalto.fi, Tatiana.Minav@aalto.fi, and Matti.Pietola@aalto.fi
}

\begin{abstract}
Environmental restrictions and economic opportunities create demand to investigate the potential of further hybridization of non-road mobile machinery (NRMM). Many proposals for energy saving in hydraulic systems have been researched. In addition to well-established methods, there are zonal or decentralized hydraulics - an approach first introduced in the aircraft industry. In a fully decentralized system, the hydraulic pumps are disconnected from the engine and replaced with hydraulic power packs distributed throughout the system. In this study, decentralized hydraulics are realized with a direct driven hydraulics drive (DDH). By applying DDH, further hybridization can be achieved which will lead to increased productivity, minimized energy consumption, and robust performance in mobile machines operating in various environments. Therefore, the aim of this paper is to investigate the energy efficiency of the excavator hydraulic system equipped with DDH under typical digging cycles. For this purpose, a model which coupled multi-body dynamics, hydraulic system, and an electric motor is developed in the Matlab Simulink environment. Simulation results are validated by a simplified representation of micro excavator (one example of DDH) as a proof of concept.
\end{abstract}

Keywords: Decentralized hydraulics, Construction machinery, Direct driven hydraulics (DDH), Excavator, Energy Efficiency, Energy consumption distribution

\section{Introduction}

The rapid rise of oil prices and government-enforced $\mathrm{CO}_{2}$ regulations lead to increasing demand for energy efficient construction machinery [1], such as excavators and wheel loaders. Electric and hybrid drives are seen as a solution to meet these requirements. In particular, non-road mobile machinery (NRMM) is a challenging field of electrification and hybridization applications due to duty cycles which may include high and short power peaks and extreme working conditions.

In a conventional excavator, the hydraulic power corresponding to the maximum workload is always supplied from a pump, and excessive power is dissipated as heat. It is often difficult to reduce input power, even during lowworkload operation, because combined controls of actuators require distribution of flows and interflows [2]. In addition, potential and kinetic energies at the time of lowering and slewing stoppage of attachments are also dissipated as heat. Multi-actuator construction machinery is often equipped with load sensing (LS) systems. In LS systems of hydraulic excavators, the supply pressure of a pump is adjusted to match the highest load pressure plus a constant pressure offset. When multiple actuators operate simultaneously, the power losses of lower-load actuators are particularly significant. Up to $35 \%$ of the energy losses during the working cycle could be avoided by removing the control valves in a typical digging cycle, and up to an additional $8 \%$ of the total energy could be recovered [3]. State-of-the-art, diverse hybrid systems are developed for construction machinery, like series or parallel hybrid hydraulic excavators [4]. The hybrid system allows eliminating the power peaks normally required from the engine. Low-varying engine operation saves significant amounts of fuel, prolongs the engine lifetime, and lowers maintenance costs.

Market demand has led to examples such as the Logset hybrid [5], Komatsu 20-ton parallel hybrid excavator [6], and Hitachi ZH200 hydraulic hybrid excavator [7]. Many proposals for energy saving in hydraulic systems have been discussed in the literature [8].

Rising trends in the industry include valveless or displacement control. An example of displacement control of actuators was realized in [9], where authors demonstrated potential engine downsizing up to $50 \%$ in a mini-excavator. Another recently introduced energy saving method is the socalled common pressure rail. In [10], it was shown that fuel consumption can be reduced $21 \%$ compared with the original LS excavator. 
In addition to well-established methods, there is zonal or decentralized hydraulics - an approach first introduced in the aircraft industry. Simplifying its design as well as broadening its orientation and performance options will support similar development in construction equipment. In a fully decentralized system, the hydraulic pumps are disconnected from the engine and replaced within hydraulic power packs distributed throughout the system [11].

Figure 1 shows the theoretical efficiencies of the different configurations for construction machinery, based on various assumptions. Direct driven hydraulics (DDH) as a variation of pump control demonstrates the best result concerning parasitic losses.
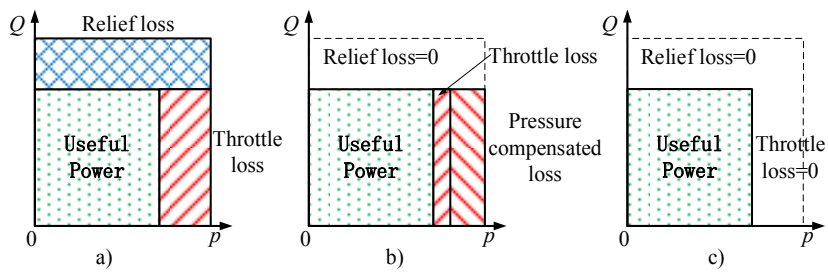

Figure 1: Comparison of differing hydraulic systems. a) convectional control, b) $L S$, c) direct driven hydraulics or pump control.

The goal of this research is to apply the concept of decentralized hydraulics in micro excavators. The concept will be realized by DDH. Figure 2 illustrates converting a conventional micro excavator into an excavator equipped with actuators driven by DDH independently. The swing motions are driven by an electric motor and the kinetic energy of the upper body is regenerated into electric energy when the swing stops.

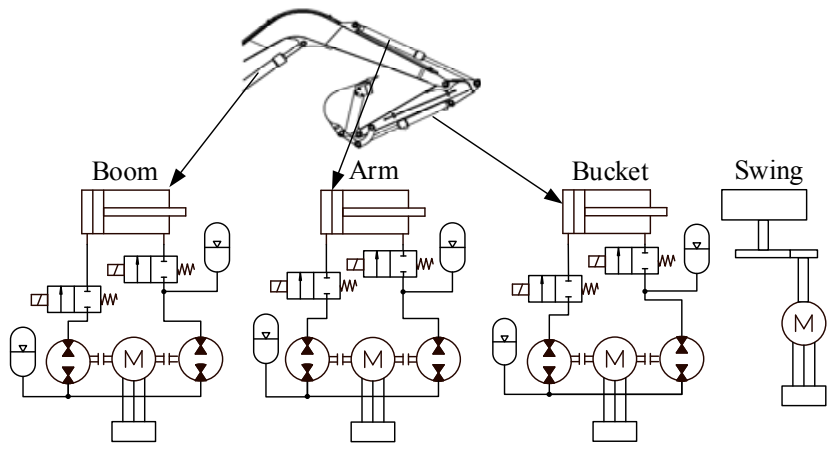

Figure 2: Simplified schematics of DDH excavator.

DDH combines the best properties of traditional hydraulics and electric intelligence allowing the following benefits to be achieved in construction machinery:

- $\quad$ easy electrification of construction machinery

- higher efficiency compared to conventional machines

- reduction of potential leakage points

- smoothness and precision of movements

- power-on-demand control

- potential energy regeneration

In this research, a 1-ton class JCB micro excavator was chosen as the test case. In [12], this excavator was electrified by replacing the $14 \mathrm{~kW}$ diesel engine with a $10 \mathrm{~kW}$ electric motor plus four Altairnano lithium-titanate battery modules. Extension of the operation time of the micro excavator was investigated by introducing a start-stop logic system of electric motor operation to improve energy efficiency with conventional valve control. The benefits of this system were measured using an artificial working cycle test. Results show operation time can be extended by at least $50 \%$ compared to the original system [12].

By applying decentralized hydraulics to the existing platform of a fully electric excavator and realizing a power-on-demand strategy, further improvement in the excavator operation time can be achieved. Consequently, the aim of this paper is to investigate the energy efficiency of an excavator hydraulic system with DDH for typical digging cycles [13]. For this purpose, a coupled multi-body dynamics, hydraulic system, and electric model is developed in the Matlab Simulink environment. Simulation results are validated by a simplified representation of micro excavator.

The remainder of this paper is organized as follows. The case study is presented in Section 2, where Sections 2.1 and 2.2 present principles and a detailed description of the developed Matlab/Simulink model. The results of simulation and experimental investigation are described in Sections 3 and 4, respectively. Finally, Section 5 and 6 contain discussion and concluding remarks.

\section{Study case: excavator with DDH}

In this study, a micro excavator is used as an example application of DDH to achieve a more efficient construction machinery. In the future, this results of this study could be implemented to other NRMM.

Internal gear motors are adopted for DDH units, with operating mode can be switching between pumping and motoring. To avoid confusion, from here on these will be referred to as pump/motors.

\subsection{Principle}

As shown in fig. 2, the original valve control system for boom, arm and bucket is replaced with three DDH units respectively. In the DDH unit, a fixed displacement pump/motor with a speed-controlled electric servo motor directly controls the amount of hydraulic oil pumped into and out from the system. The hydraulic pump/motor creates a flow depending on the rotating speed of the servo motor. Additionally, a hydraulic accumulator is used as a conventional tank replacement [14].

In DDH, dimensions of a utilized double-acting single-rod cylinder bring requirements for pump/motors. Therefore, an ideal cylinder ratio $R_{\text {ideal }}$ was established for choosing pump displacement, where $R_{\text {ideal }}$ is the surface area ratio between the annulus area and the piston of each cylinder. Due to available pump units, the realized pump displacement ratio $R_{\text {real }}$ differs from $R_{\text {ideal }}$, where $R_{\text {real }}$ is the displacement ratio between pumps connecting to the rod side and the piston side. This leads to sizing error in some cases if pump unit is slightly under-dimensioned. Thus, fluid from the cylinder B-chamber is not pumped out at a corresponding rate to that of the fluid 
pumped into the A-chamber. This leads to a rise of pressure in the B-chamber, which should be mitigated. In this study, the sizing error is mitigated by adding hydraulic accumulator $\mathrm{D}$ as shown in fig. 2 .

\subsection{Modeling}

In order to acquire the dynamic response and energy consumption distribution of the actuators, this study constructed a particular model in Matlab/Simulink, which integrated with mechanics, hydraulics, electrics and control systems of the micro excavator.

\subsubsection{Mechanical model}

The prototype is a 1-ton class JCB micro excavator with a conventional valve control system, as shown in fig. $3 \mathrm{a}$. The $3 \mathrm{D}$ solid mechanical model was constructed and the material was assigned to each part in PTC Creo. As shown in the fig. $3 \mathrm{~b}$, the multibody dynamic model was created by exporting from PTC Creo and importing into Matlab Simscape using Simscape Multibody Link Plug-In.

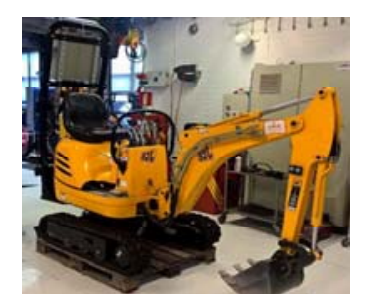

a)

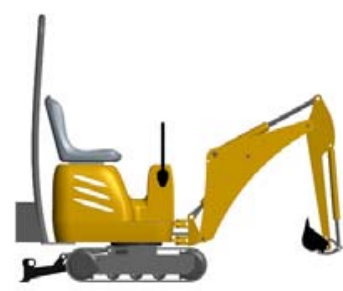

b)
Figure 3: a) The prototype, b) multibody dynamic model.

\subsubsection{Hydraulic model}

The mathematical models of cylinder, pump/motors, accumulators and pipes of DDH are built in Matlab/Simulink. Most of their detailed explanations refer to work in [15].

In order to make accurate energy efficiency calculations, Vivoil gear motors with displacements of $22.8 \cdot 10^{-6}$ and $14.4 \cdot 10^{-6} \mathrm{~m}^{3} / \mathrm{rev}$, with leakage submodels obtained by measurements in [16], were chosen respectively and adopted for all three DDH units.

The parameters of cylinders were obtained from the micro excavator and the ideal pump/motor ratios $R_{\text {ideal }}$ and real pump/motor ratios $R_{\text {real }}$ are shown in Table 1 . The sizing errors for bucket cylinder and arm cylinder are both $1.57 \%$, namely less than $2 \%$, which would not cause excess pressure [15]. However, the pump/motor ratio for boom demands compensation for the sizing error.

Table 1: Parameters of each DDH.

\begin{tabular}{|c|c|c|c|c|c|}
\hline \multirow{2}{*}{} & \multirow{2}{*}{$\begin{array}{c}\text { Cylinder } \\
{[\mathrm{mm}]}\end{array}$} & \multicolumn{2}{|c|}{ Ratio } & Accumulator & Accumulator \\
\cline { 3 - 6 } & & $R_{\text {ideal }}$ & $R_{\text {real }}$ & $\mathrm{C}$ & $\mathrm{D}$ \\
\hline Boom & $60 / 30 \times 325$ & 0.75 & 0.63 & $0.7 \mathrm{~L} @ 1 \mathrm{bar}$ & $0.7 \mathrm{~L} @ 10 \mathrm{bar}$ \\
\hline Arm & $50 / 30 \times 400$ & 0.64 & 0.63 & $0.7 \mathrm{~L} @ 1 \mathrm{bar}$ & - \\
\hline Bucket & $50 / 30 \times 290$ & 0.64 & 0.63 & $0.7 \mathrm{~L} @ 1 \mathrm{bar}$ & - \\
\hline
\end{tabular}

Considering the load of boom cylinder is mainly negative force, the compensating hydraulic accumulator $\mathrm{D}$ is located at the opposite side of the rod and another one $\mathrm{C}$ operating as tank is mounted between two pump/motors as shown in fig. 4. As a result, each DDH model consists of pump/motors, a hydraulic cylinder, two on/off valve and one or two hydraulic accumulators.

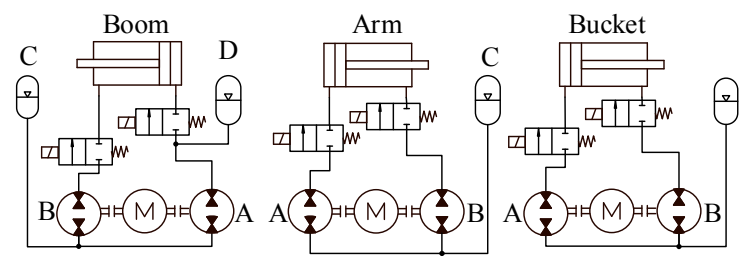

Figure 4: Modified DDH for micro excavator.

Figure 5 illustrates the micro excavator model with multibody and a triple DDH built in Matlab/Simulink.

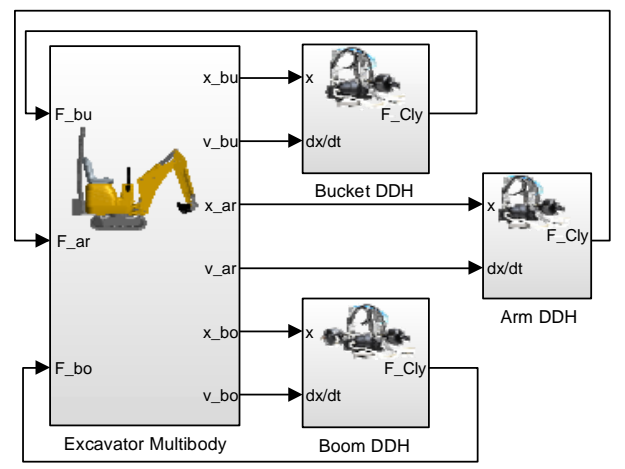

Figure 5: Simulink model of excavator with DDH.

Pump/motor leakage consists of all internal and external leakage flows as a function of the pressure difference over the pump and the pump flow equation is given by eq. (1):

$$
q_{\mathrm{P}}=V_{\mathrm{P}} n-q_{\mathrm{L}} .
$$

The pump produces a flow $q_{\mathrm{P}}$ which is dependent on the rotational speed $n$, its displacement $V_{\mathrm{P}}$ and leakage flow $q_{\mathrm{L}}$. $q_{\mathrm{L}}$ is a function of the pressure difference of over the pump at $20^{\circ} \mathrm{C}$, obtained by a cross sectional linear regression after measurements [16], as shown by eq. (2).

$$
q_{\mathrm{L}}=\alpha+\beta \Delta p+\gamma \sqrt{\Delta p}+\varepsilon,
$$

where $\alpha, \beta$ and $\gamma$ are regression coefficients as shown in Table 2, $\Delta p$ is pressure difference of over the pump, and $\varepsilon$ is an error term.

Table 2: Leakage model coefficients [16].

\begin{tabular}{|c|c|c|c|c|}
\hline Pump & $\alpha$ & $\beta$ & $\gamma$ & $\varepsilon$ \\
\hline $22.8 \mathrm{~mL} / \mathrm{rev}$ & $-3.61 \cdot 10^{-4}$ & $-2.66 \cdot 10^{-13}$ & $4.44 \cdot 10^{-9}$ & $1.89 \cdot 10^{-4}$ \\
\hline $14.4 \mathrm{~mL} / \mathrm{rev}$ & $-2.60 \cdot 10^{-4}$ & $6.09 \cdot 10^{-13}$ & $1.96 \cdot 10^{-9}$ & $1.23 \cdot 10^{-4}$ \\
\hline
\end{tabular}

The model describing the pressure in an asymmetrical cylinder is divided into two parts as shown in eq. (3) and (4):

$$
\begin{aligned}
& \dot{p}_{\mathrm{A}}=\frac{B(p)}{V_{0 \mathrm{~A}}+A_{\mathrm{A}} x}\left[q_{\mathrm{A}}-K_{\mathrm{L}}\left(p_{\mathrm{A}}-p_{\mathrm{B}}\right)-A_{\mathrm{A}} \dot{x}\right], \\
& \dot{p}_{\mathrm{B}}=\frac{B(p)}{V_{0 \mathrm{~B}}+A_{\mathrm{B}}\left(x_{\max -x)}\right.}\left[q_{\mathrm{B}}+K_{\mathrm{L}}\left(p_{\mathrm{A}}-p_{\mathrm{B}}\right)+A_{\mathrm{B}} \dot{x}\right],
\end{aligned}
$$

where $B(p)$ is the bulk modulus for oil varying with pressure; $V_{0 \mathrm{~A}}$ and $V_{0 \mathrm{~B}}$ are the dead volume of the cylinder's piston side chambers; $K_{\mathrm{L}}$ is the leakage constant between the cylinder 
chambers, $\mathrm{A}$ and $\mathrm{B} ; q_{\mathrm{A}}$ and $q_{\mathrm{B}}$ are the flows into the cylinder's piston side respective chambers.

$$
F=\left(p_{\mathrm{A}} A_{\mathrm{A}}-p_{\mathrm{B}} A_{\mathrm{B}}\right)-F_{\mathrm{r}}-F_{\text {end }},
$$

where the friction force $F_{\mathrm{r}}$ of the cylinder is calculated by utilizing the LuGre model [17], and the simulation parameters are from reference [16], which have been verified by measurements; $F_{\text {end }}$ is the end force.

\subsubsection{Electric drive}

The model of 3 phase permanent magnet synchronous motor (PMSM) was built in Matlab/Simulink [18]. In this study, it is assumed that the utilized synchronous machine has surfacemounted permanent magnets, rotor is magnetically round (non-salient) and has the same reluctance along any axis through the center of the electric machine. The vector control $i_{\mathrm{d}}=0$ is utilized for controlling of PMSM.

Space vectors transformation from a-b-c phase into equivalent $d q$ quantities is implemented. The $d q$ transformation is used for a simplified application of control method for electric motor.

Applying these simplifications, electromagnetic torque can be calculated as shown in eq. (6).

$$
T_{\mathrm{em}}=\frac{N \mathrm{p}}{2} \lambda_{\mathrm{fd}} i_{\mathrm{dq}},
$$

where $N_{\mathrm{p}}$ is pole pairs, $\lambda_{\mathrm{fd}}$ is the flux linkage of the stator $d$ winding that produced by the rotor magnets, $i_{\mathrm{sq}}$ is stator current in $q$ axis.

Stator voltages in $d q$ transformation are shown in eq. (7) and (8):

$$
\begin{gathered}
v_{\mathrm{sd}}=R_{\mathrm{s}} i_{\mathrm{sd}}-\omega_{\mathrm{m}} L_{\mathrm{s}} i_{\mathrm{sq}}, \\
v_{\mathrm{sq}}=R_{\mathrm{s}} i_{\mathrm{sq}}+\omega_{\mathrm{m}} L_{\mathrm{s}} i_{\mathrm{sd}}+\omega_{\mathrm{m}} \lambda_{\mathrm{fd}},
\end{gathered}
$$

where $L_{\mathrm{s}}$ is stator inductance, $R_{\mathrm{s}}$ is stator resistance, $i_{\mathrm{sd}}$ is stator current in $d$ axis and $\omega_{\mathrm{m}}$ is related to actual rotor speed $\omega_{\text {mech }}$ as shown in eq. (9).

$$
\omega_{\mathrm{m}}=\frac{N \mathrm{p}}{2} \omega_{\mathrm{mech}} .
$$

The electromechanical torque acts to the load connected to the motor, resulting in actual (mechanical) speed of the rotor $\omega_{\text {mech }}$ :

$$
\frac{d \omega_{\mathrm{mech}}}{d t}=\frac{T_{\mathrm{em}}-T_{\mathrm{L}}}{J_{\mathrm{eq}}},
$$

where $J_{\text {eq }}$ is combined motor load inertia, $T_{1}$ is load torque.

PI controllers are utilized for realization of $i_{\mathrm{d}}=0$ control for adjusting $i_{\mathrm{d}}$ and $i_{\mathrm{q}}$ currents. In this research, it is assumed that the inverter has fixed switching losses. In realized design, the current feedback controller (PI control) is tuned for the desired phase margin at the chosen open-loop crossover frequency. The speed feedback controller (self-adjusting parameter fuzzy PID control), is used to adjust the shaft speed to be independent of the load-torque disturbance coming from hydraulics, according to a reference signal. The parameter of the motor was set according to its datasheet as shown in Table 3.
Table 3: PMSM characteristics [19].

\begin{tabular}{|c|c|}
\hline Parameter & Value \\
\hline Rated Speed & $3000 \mathrm{rpm}$ \\
\hline Rated torque & $8.1 \mathrm{~N} \cdot \mathrm{m}$ \\
\hline Stall current & $5.9 \mathrm{~A}$ \\
\hline Rated power & $2.54 \mathrm{~kW}$ \\
\hline$R_{\mathrm{s}}$ - Resistance(phase) & $2.02 \Omega$ \\
\hline$L_{\mathrm{s}}$ - Inductance(phase) & $13.27 \cdot 10^{-3} \mathrm{H}$ \\
\hline Inertia & $9.0 \cdot 10^{-4} \mathrm{~kg} \cdot \mathrm{m}^{2}$ \\
\hline Stall Torque & $9.4 \mathrm{~N} \cdot \mathrm{m}$ \\
\hline Peak torque & $28.2 \mathrm{~N} \cdot \mathrm{m}$ \\
\hline
\end{tabular}

2.2.4 System control

In this model, closed-loop PID controls between the frequency converter and the electric motor, and position control with P regulator are utilized, as illustrated in fig. 6 .

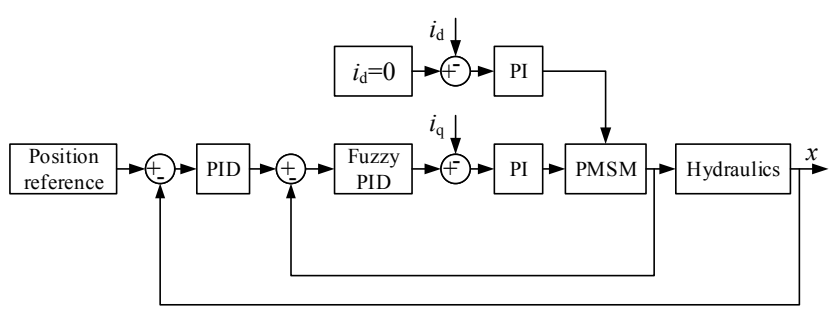

Figure 6: System control schematic.

\section{Simulation and results}

In this simulation, a typical excavator digging cycle was selected for simulation. This cycle represents an excavator digging a load of earth, rotating, releasing the load onto a pile, and then returning to its initial position [3]. The cycle inputs shown in fig. 7 are the relative cylinder displacements.

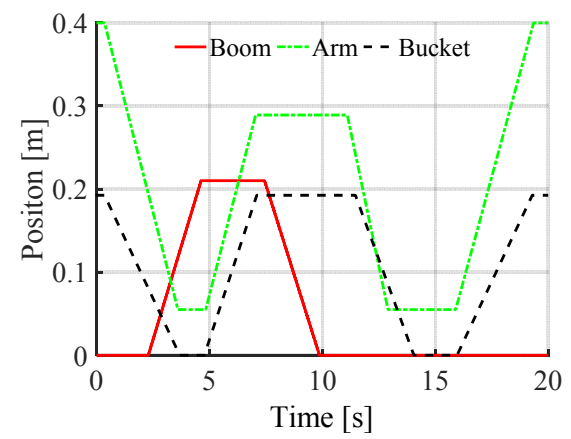

Figure 7: Input reference of a typical digging cycle [3].

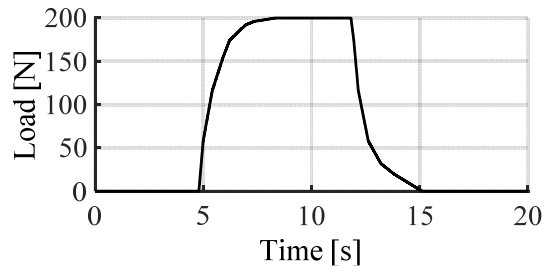

Figure 8: Digging load of loose dry dirt [3].

The rated capability of the bucket is $17 \mathrm{~L}$, and the density of loose dry dirt is $1220 \mathrm{~kg} / \mathrm{m}^{3}$. Consequently, a time-dependent 
bucket load is $20 \mathrm{~kg}$, which was implemented into the working cycle [3]. The load increases to a $20 \mathrm{~kg}$ of dirt as the bucket rotates in loading mode and then decreases to zero as the bucket rotates in the dumping motion, as provided in fig. 8. The outputs of position and velocity adopting position control in this cycle are presented in fig. 9.

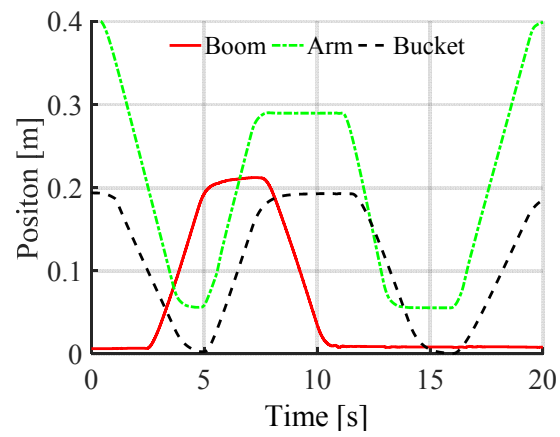

a)

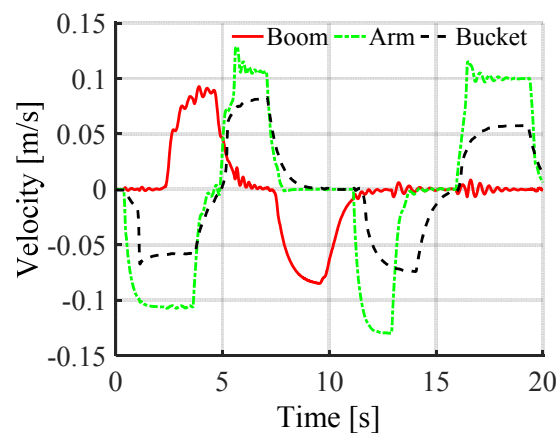

b)

Figure 9: a) Position output, b) velocity output.

Table 4: Definitions of power and energy.

\begin{tabular}{|c|c|}
\hline Equation & Symbol \\
\hline$P_{\text {cylinder }}=\left(p_{\mathrm{A}} A_{\mathrm{A}}-p_{\mathrm{B}} A_{\mathrm{B}}\right) \cdot \dot{\chi}$ & $\begin{array}{l}P_{\text {cylinder }}-\text { input power of cylinder, } \mathrm{W} \\
p_{\mathrm{A}}, p_{\mathrm{B}}-\text { pressure of piston side and rod side } \\
\text { of cylinder, } \mathrm{Pa} \\
A_{\mathrm{A}}, A_{\mathrm{B}}-\text { effective cross area of cylinder } \\
\text { piston side and rod side, } \mathrm{m}^{2} \\
\dot{x}-\text { velocity of cylinder piston, } \mathrm{m} / \mathrm{s}\end{array}$ \\
\hline$P_{\text {pump }}=T_{\mathrm{P}} n_{\mathrm{P}}$ & $\begin{array}{l}P_{\text {pump }}-\text { input power of pump, } \mathrm{W} \\
T_{\mathrm{P}}-\text { torque of pump shaft, } \mathrm{N} \cdot \mathrm{m} \\
n_{\mathrm{P}}-\text { speed of pump shaft, } \mathrm{rad} / \mathrm{s}\end{array}$ \\
\hline$P_{\text {motor }}=T_{\mathrm{M}} n_{\mathrm{M}}$ & $\begin{array}{l}P_{\text {motor }}-\text { output power of motor, } \mathrm{W} \\
T_{\mathrm{M}}-\text { torque of motor shaft, } \mathrm{N} \cdot \mathrm{m} \\
n_{\mathrm{M}}-\text { speed of motor shaft, } \mathrm{rad} / \mathrm{s}\end{array}$ \\
\hline$P_{\mathrm{PMSM}}=v_{\mathrm{a}} i_{\mathrm{a}}+v_{\mathrm{b}} i_{\mathrm{b}}+v_{\mathrm{c}} i_{\mathrm{c}}$ & $\begin{array}{l}P_{\mathrm{PMSM}}-\text { input power of PMSM, } \mathrm{W} \\
v_{\mathrm{a}}, v_{\mathrm{b}}, v_{\mathrm{c}}-\text { phase voltage, } \mathrm{V} \\
i_{\mathrm{a}}, i_{\mathrm{b}}, i_{\mathrm{c}}-\text { phase current, } \mathrm{A}\end{array}$ \\
\hline$E_{\text {cylinder }}=\int P_{\text {cylinder }} \mathrm{d} t$ & 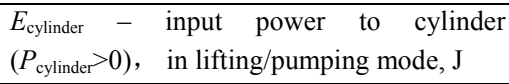 \\
\hline$E_{\mathrm{PMSM}}=\int P_{\mathrm{PMSM}} \mathrm{d} t$ & $\begin{array}{l}E_{\mathrm{PMSM}}-\text { energy consumed by } \mathrm{PMSM} \\
\left(P_{\mathrm{PMSM}}>0\right), \mathrm{J}\end{array}$ \\
\hline$E_{\text {Regeneration }}=\int P_{\mathrm{PMSM}} \mathrm{d} t$ & $\begin{array}{l}E_{\mathrm{PMSM}}-\text { energy regenerated by } \mathrm{PMSM} \\
\left(P_{\mathrm{PMSM}}<0\right), \mathrm{J}\end{array}$ \\
\hline$\eta=\frac{E_{\text {cylinder }}}{E_{\mathrm{PMSM}}}$ & $\eta$, Energy efficiency of DDH, \% \\
\hline
\end{tabular}

The main objective of this part is to compute the energy efficiency of DDH units and overall efficiency of them in the typical digging cycle, and to discover the energy recovery potential. The power of components was calculated as shown in Table 4, and the energy was obtained by integrating the power.

The cylinder power is calculated as the product of the hydraulic pressure force in the respective actuator and its velocity, including frictional effects. Calculation of $\eta$ efficiency includes following losses: all internal and external leakage of pump, hydromechanical friction of pump, pressure loss of cylinder outlet caused by extra pressure rise due to dynamic flowrate error between ideal ratio $R_{\text {ideal }}$ of cylinder and real ratio $R_{\text {real }}$ of pumps.

When boom goes down, the pump/motor B runs in motoring mode. Therefore, PMSM generates electricity, absorbing the potential energy as shown in fig. 10. While boom lifting, pump/motor B runs in pumping mode.

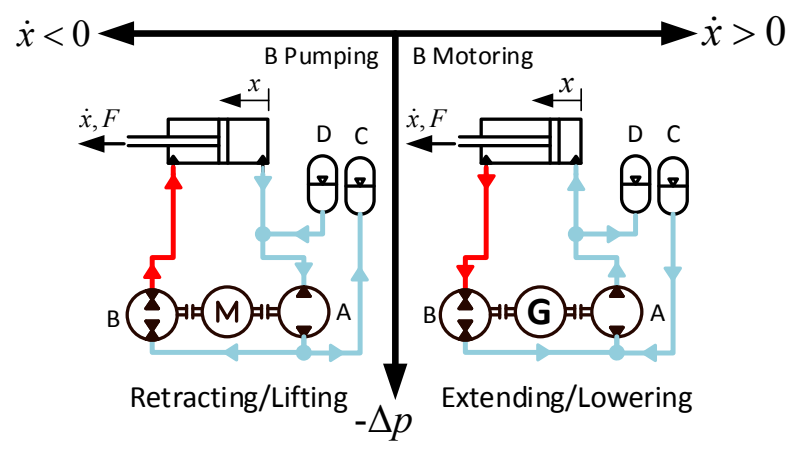

Figure 10: Operating mode of boom pump/motor B and PMSM.
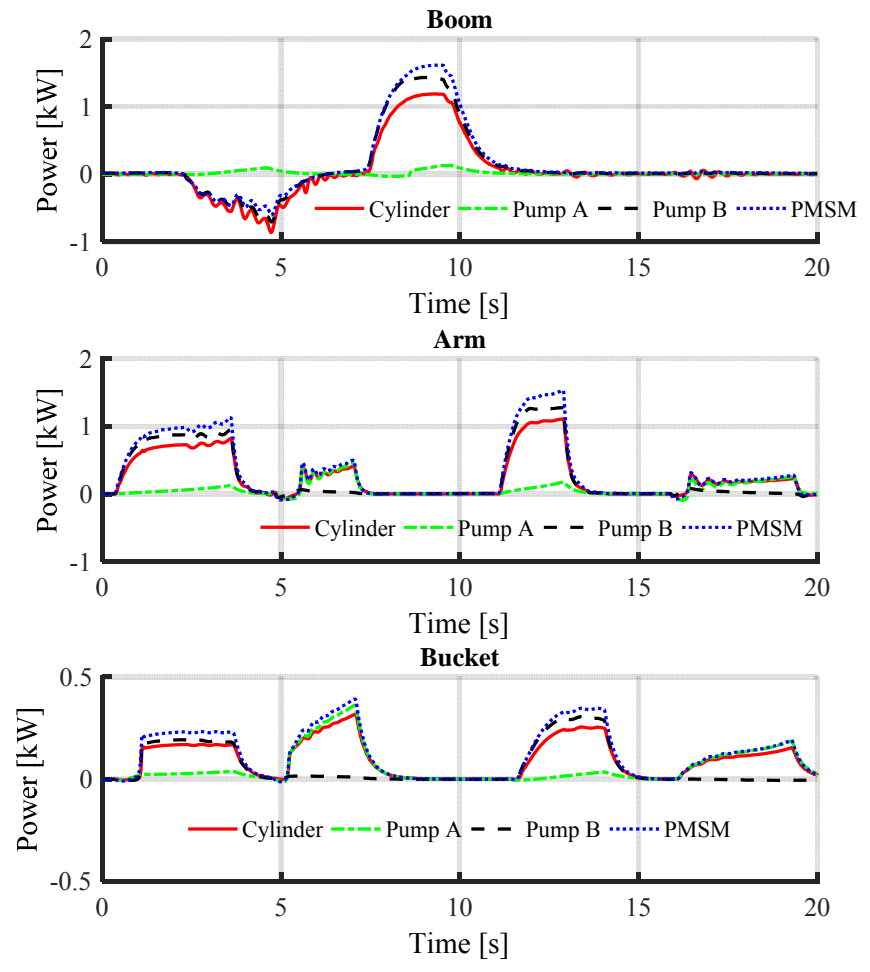

Figure 11: Simulated power consumed by each DDH component for boom, arm, and bucket. 
In boom DDH (fig. 11), the pump/motor B was in motoring mode from 2.5 to $5.5 \mathrm{~s}$ while lowering, and in pumping mode from 7.5 to $10.5 \mathrm{~s}$ while lifting. The maximum power consumed by pump A is $0.12 \mathrm{~kW}$ in a short period during lifting, to charge the hydraulic accumulator $\mathrm{C}$.

After calculation, the energy consumption amount of the cylinder and input energy for the PMSM are presented in Table 5. Furthermore, the energy efficiency of each unit is figured out. The results show the energy efficiency of the boom DDH, arm DDH, and bucket DDH was $67.5 \%, 75.4 \%$, $77.5 \%$ respectively for performed cycle (fig. 9a). The overall efficiency of front attachment with three DDH units was found to approximate to $73.3 \%$, much higher than $31.4 \%$ (efficiency of a 5-ton excavator with LS system in [3]). Furthermore, the potential energy recovery for boom DDH estimated as $1.54 \mathrm{~kJ}$.

Table 5: Energy consumption and efficiency.

\begin{tabular}{|l|l|c|c|}
\hline \multicolumn{2}{|l|}{ DDH } & Energy [kJ] & Efficiency [\%] \\
\hline \multirow{3}{*}{ Boom } & Cylinder & 2.90 & \multirow{2}{*}{67.5} \\
\cline { 2 - 4 } & PMSM & 4.29 & - \\
\cline { 2 - 4 } & Regeneration & 1.54 & - \\
\hline \multirow{4}{*}{ Arm } & Cylinder & 5.16 & 75.4 \\
\cline { 2 - 4 } & PMSM & 6.84 & - \\
\cline { 2 - 4 } & Regeneration & 0.04 & 77.5 \\
\hline \multirow{3}{*}{ Bucket } & Cylinder & 1.96 & - \\
\cline { 2 - 4 } & PMSM & 2.54 & \multirow{2}{*}{} \\
\cline { 2 - 4 } & Regeneration & 0 & \\
\hline
\end{tabular}

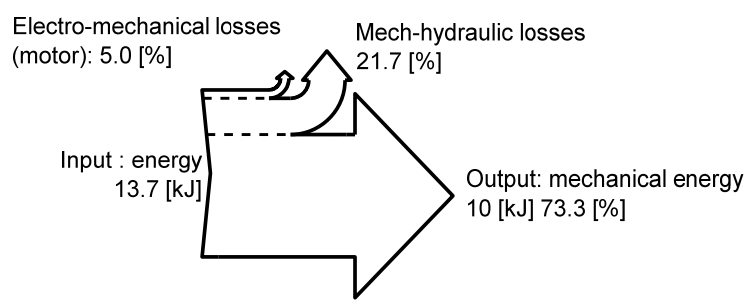

Figure 12: Energy flow of DDH system.

Additionally, the Sankey diagram of the decentralized excavator with a triple DDH units is shown in fig. 12. The electro-mechanical losses are 5\%, due to $95 \%$ fixed efficiency in the PMSM model. The mech-hydraulic losses account for $21.7 \%$, including hydro-mechanical friction (hydro-mechanical efficiency 0.85, estimated from datasheet), internal and external leakage, and pressure losses caused by sizing error. $73.3 \%$ of overall energy is consumed by cylinders and loads.

\section{Validation}

For simplicity, a standalone DDH will be utilized as a proof of concept to validate simulation results for the micro excavator. In this validation study, it is assumed a standalone DDH power pack represents bucket or arm cylinder of the excavator, due to one degree of freedom (DOF) and the same required pump/motor displacement ratio $R_{\text {real }}$. Figure 12 illustrates the proposed validation setup with schematic and the data acquisition system.

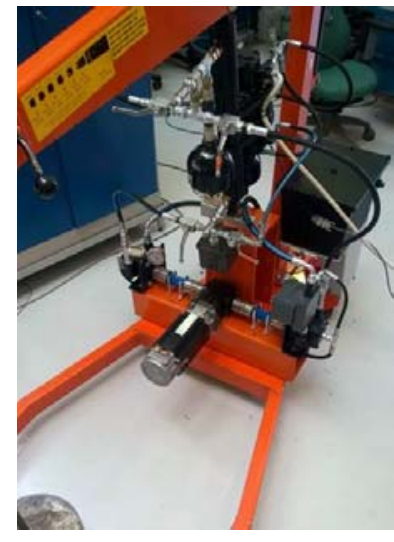

a)

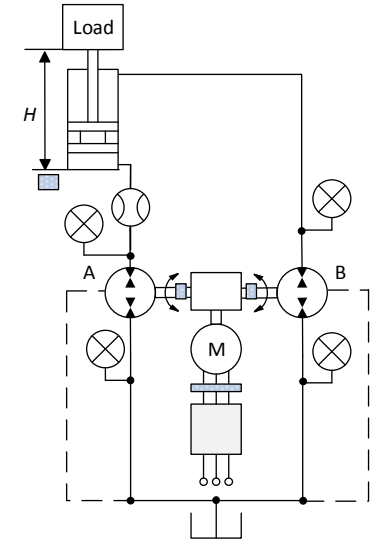

b)
Figure 12: a) Standalone DDH (crane), b) schematic.

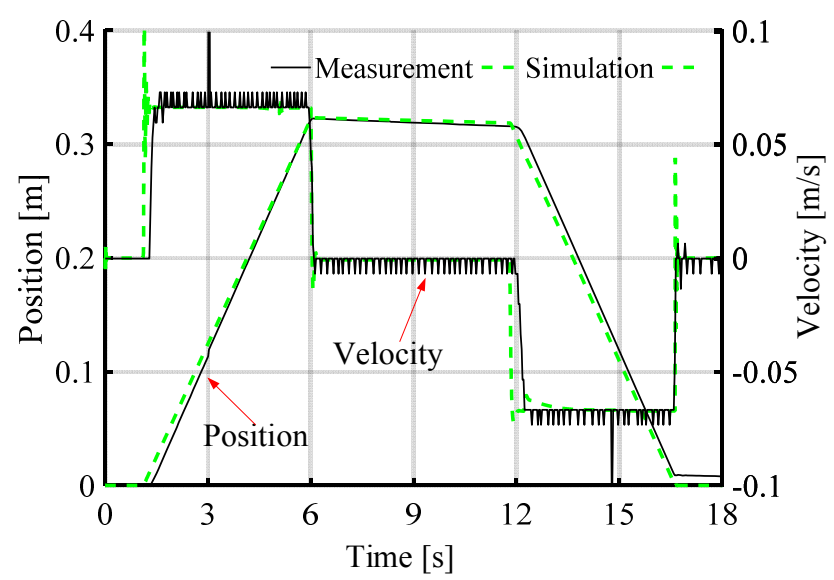

a)

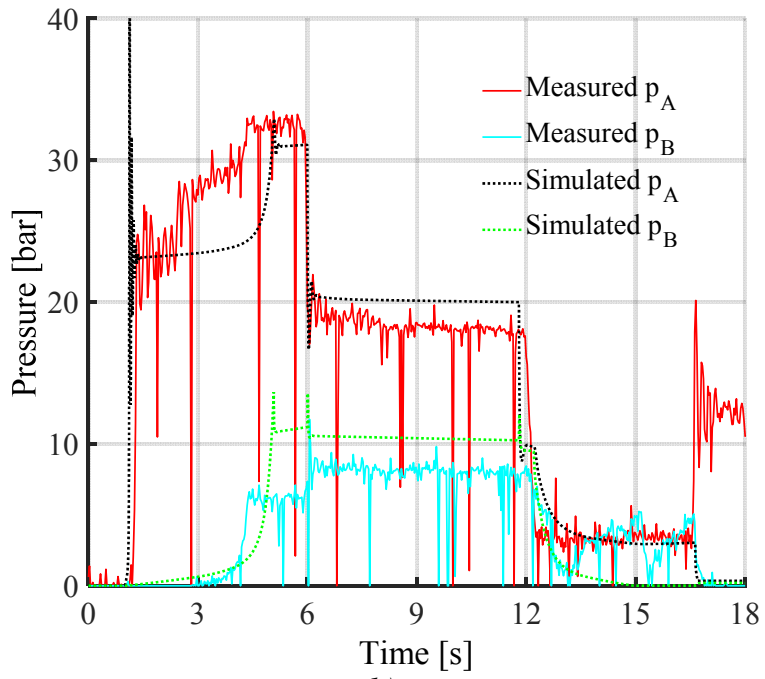

b)

Figure 13: Validation of simulation: a) velocity and positon, b) pressure of chamber $A$ and $B$.

In the proposed validation setup, the speed and position control of a double-acting cylinder is implemented directly with an electric motor drive in a closed-loop system without conventional control valves [14]. 
An example of measurement data of standalone DDH with payload of $120 \mathrm{~kg}$ and rotating motor speed $750 \mathrm{rpm}$ is displayed in fig. 13. The simulation results of position, velocity, and pressures of chamber A and chamber B show acceptable accuracy, compared with the measurement results. Therefore, the developed model can be used to evaluate the system performance of decentralized excavator.

\section{Discussion}

In this research, a typical working cycle for a micro excavator was studied. Initial investigation of the excavator with decentralized hydraulics is based on a Matlab/Simulink model coupled with multibody dynamics. The purpose of the model is to investigate the efficiency of decentralized hydraulics for micro excavator applications.

The model was developed on the basis of following simplifications. The LuGre model was chosen for cylinder friction, in which temperature and pressure difference are not taken into account. The pump leakage model considers only pressure difference and does not take into account speed and temperature variation. The on/off valves are not included in this model, and piping is regarded as static fluid volumes. For this initial stage of research, these simplifications are considered acceptable. However, for future development, some of these simplifications should be taken into account. Cavitation problems were not investigated yet in this study, but should be included in the future.

The load model was simplified, as the actual digging cycle does not have penetration into the pile. This was excluded due to the complexity of the terra-mechanical forces. At the moment, data acquisition is not available for quantifying these forces.

System control for DDH and decentralized hydraulics was not the focus of this research and was not investigated in detail. A self-adjusting fuzzy PID control was implemented as a speed control for the electric motor, using a fixed PID control as current control (electric motor vector control $\mathrm{id}=0$ ) and position control (cylinder) as a response to load-torque disturbance coming from the hydraulics.

Since decentralized hydraulics were implemented without a proportional control valve, the damping of the system is low compared to conventional systems, which leads to some oscillations. Therefore, the control strategy of the DDH can be improved in the future. Further evaluation of the dynamic performance of the hydraulic system should be made. In addition, the properties of the electric motor should be considered by the model and evaluated.

For simplicity, it is assumed that a standalone DDH power pack represents a bucket or arm cylinder of the excavator, due to one degree of freedom (DOF) motion. Experimental data is utilized to validate the developed model and used as proofof-concept of decentralized hydraulics applied to the micro excavator.

Validation of the model showed acceptable results. The detail level of the model could be improved based on validation results.
Efficiency behaviors of DDH components and the overall efficiency of the triple DDH system were determined. The efficiency estimation was based on simulation combining data from manufacturers and experiment. Productivity and efficiency analysis should be performed for the proposed decentralized approach to investigate the benefits of this system in more detail.

Table 5 shows system efficiency is in the range of 67.5 to $77.5 \%$. Among three DDH units, boom DDH has the lowest efficiency due to pressure losses caused by the sizing mismatch and higher leakage produced by the higher load. In fig. 12, Sankey diagram shows details about the energy loss distribution and the overall efficiency is $73.3 \%$. The dominate losses are hydro-mechanical and simulation results show higher efficiency compared to LS systems (literature state-ofthe-art [3]). However, future detailed modelling will affect these values, and increased energy consumption due to temperature, pressure, viscosity, and friction. As part of this project, decentralized hydraulics should be compared with conventional valve-controlled systems in modelling and experiment, in order to demonstrate the full benefits of this approach.

Regeneration of energy with DDH was shown, which gives additional benefits for this kind of system. The potential energy recovery for the boom DDH was estimated as $1.54 \mathrm{~kJ}$, which can be transformed into electrical power. In this study, the inverter for the DDH was directly powered from the electrical grid, and the energy storage, inverter, power electronics were not considered in this stage of research. Consequently, the regenerated potential energy was not stored. However, energy storage could be accomplished using a battery or super capacitor. Disadvantages are additional components expenses needed. Energy storage and its management system, power electronics, and three inverters will affect price, efficiency, and maintenance of the decentralized hydraulics. However, further investigation of these components will be included in the near future.

\section{Conclusion}

This research has shown that typical cycle control and potential energy recovery by DDH for work-set are feasible in a micro excavator. Efficiency behaviors of DDH components and the overall efficiencies of the triple DDH system were determined. The efficiency estimation was based on simulation combining data from manufacturers and experiment.

According to simulation, the energy efficiency of the boom $\mathrm{DDH}$, arm DDH, and bucket DDH was $67.5 \%, 75.4 \%$, $77.5 \%$, respectively. Furthermore, the potential energy recovery for boom DDH was estimated as $1.54 \mathrm{~kJ}$.

For simplicity, a standalone DDH was utilized as a proof of concept to validate simulation results for the micro excavator.

The simulation showed that combining the efficiency of three DDH units and energy recovery for each actuator, the overall efficiency could reach $73.3 \%$ for performed cycle. It is higher than efficiency of LS system (a 5-ton LS excavator). 
Therefore, the decentralized approach could be suggested for construction equipment.

\section{Acknowledgments}

This research was enabled by the financial support of the Tekes (project EL-Zon), internal funding from the Department of Mechanical Engineering at Aalto University, Finland. This work was partly supported by the Natural Science Foundation of Fujian Province, China (No. 2016J01203) and by the Scientific Research Fund of Fujian University of Technology (No. GY-Z15096).

\section{Nomenclature}

\begin{tabular}{|c|c|c|}
\hline Designation & Denotation & Unit \\
\hline$F_{i}$ & Force & {$[\mathrm{N}]$} \\
\hline$p_{\mathrm{A}, \mathrm{B}}$ & Pressure & {$[\mathrm{Pa}]$} \\
\hline$B$ & Bulk modulus & {$[\mathrm{Pa}]$} \\
\hline$q$ & Flowrate & {$\left[\mathrm{m}^{3} / \mathrm{s}\right]$} \\
\hline$A$ & Area & {$\left[\mathrm{m}^{2}\right]$} \\
\hline$x$ & Displacement & {$[\mathrm{m}]$} \\
\hline$V$ & Displacement & {$\left[\mathrm{m}^{3} / \mathrm{rev}\right]$} \\
\hline$n$ & Rational speed & {$[\mathrm{rpm}]$} \\
\hline$P$ & Power & [W] \\
\hline E & Energy & {$[\mathrm{J}]$} \\
\hline$R$ & Displacement ratio & - \\
\hline$v_{\mathrm{a}, \mathrm{b}, \mathrm{c}}$ & Phase voltage & {$[\mathrm{V}]$} \\
\hline$i_{\mathrm{a}, \mathrm{b}, \mathrm{c}}$ & Phase current & {$[\mathrm{A}]$} \\
\hline$N \mathrm{p}$ & Pole pairs & - \\
\hline$i_{\mathrm{sq}}$ & Stator current in $q$ axis & {$[\mathrm{A}]$} \\
\hline$i_{\mathrm{sd}}$ & Stator current in $d$ axis & {$[\mathrm{A}]$} \\
\hline$R_{\mathrm{s}}$ & Stator resistance & {$[\mathrm{Ohm}]$} \\
\hline$L_{\mathrm{s}}$ & Stator inductance & {$[\mathrm{mH}]$} \\
\hline$\varpi_{\text {mech }}$ & Actual rotor speed & {$[\mathrm{rad} / \mathrm{s}]$} \\
\hline$\omega_{\mathrm{m}}$ & Angular speed & {$[\mathrm{rad} / \mathrm{s}]$} \\
\hline$\lambda_{\mathrm{fd}}$ & $\begin{array}{l}\text { Flux linkage of the } \\
\text { stator } d \text { winding }\end{array}$ & {$\left[\mathrm{kg} \cdot \mathrm{m}^{2} \cdot \mathrm{s}^{-2} \cdot \mathrm{A}^{-1}\right]$} \\
\hline
\end{tabular}

\section{References}

[1] Tier 4 emission standards for nonroad diesel engines, online,

https://www.dieselnet.com/standards/us/nonroad.php\#ti er4.

[2] M Kagoshima, M Komiyama, T Nanjo, and A Tsutsui. Development of new hybrid excavator. Kobelco Technology Review, (27): 39-42, 2007.
[3] J D Zimmerman, M Pelosi, C A Williamson, and M Ivantysynova. Energy consumption of an LS excavator hydraulic system. ASME 2007 International Mechanical Engineering Congress and Exposition, 117-126,2007.

[4] T Lin, Q Wang, B Hu, and W Gong. Development of hybrid powered hydraulic construction machinery. Automation in Construction, 19(1): 11-19, 2010.

[5] 12H GTE hybrid harvester, http://www.logset.com/12H_GTE_Hybrid

[6] Anon. Komatsu introduces the world's first hydraulic excavator: hybrid evolution plan for construction equipment. Komatsu press release, 05: 2008, http://www.komatsu.com/CompanyInfo/press/2008051 315113604588.html

[7] New Generation Hybrid Excavator ZH200-5B, online, http://www.hitachi.com/environment/showcase/solution /industrial/hybrid_excavator.html

[8] M. Edamura, E. S. Ishida, S. Imura, and S. Izumi. Adoption of electrification and hybrid drive for more energy-efficient construction machinery. Hitachi Review, 62(2): 118, 2013.

[9] R Hippalgaonkar, and M Ivantysynova. A series-parallel hydraulic hybrid mini-excavator with displacement controlled actuators. The 13th Scandinavian International Conference on Fluid Power, SICFP2013, June 3-5, 2013, Linköping, Sweden

[10] W Shen, J Jiang, X Su, and H Karimi. Energy saving analysis of hydraulic hybrid excavator based on common pressure rail, Hindawi, https://www.hindawi.com/journals/tswj/2013/560694/

[11] T Minav, T Lehmuspelto, P Sainio, and M Pietola. Series hybrid mining loader with zonal hydraulics. 8-10 March 2016, IFK-2016, Dresden, Germany

[12] T Hassi, A Korva, S Markkula, etc. Improving energy efficiency of an electric mini excavator. 11th International DAAAM Baltic Conference "Industrial engineering", 20-22 April 2016, Tallinn, Estonia

[13]J D Zimmerman. Towards optimal multi-actuator displacement controller mobile hydraulic systems, 2012, Purdue University: Indiana, USA.

[14] T Minav, and M Pietola. Position control of direct-driven hydraulic drive without conventional oil tank for more electric aircraft, MEA2015 More Electric Aicraft, 2015, Toulouse, France.

[15]A Järf. Flow compensation using hydraulic accumulator in direct driven hydraulic differential cylinder application and effects on energy effciency. 2016, Aalto University: Espoo, Finland. 
[16]A Järf, T Minav, and M Pietola. Nonsymmetrical flow compensation using hydraulic accumulator in direct driven differential cylinder, Proceedings of the ASME 2016 9th FPNI Ph.D. Symposium on Fluid Power, FPNI2016, October 26-28, 2016, Florianópolis, SC, Brazil

[17]C Canudas de Wit, $\mathrm{H}$ Olsson, $\mathrm{K} \mathrm{J}$ Astrom, and P Lischinsky. A new model for control of systems with friction. IEEE Transactions on automatic control 40(3): 419-425, 1995.

[18] Ned Mohan. Advanced electric drives: analysis, control, and modeling using MATLAB/Simulink. John wiley \& sons, 2014.

[19]Emerson Industrial Automation. Technical Data Unimotor FM and HD High performance AC brushless servo motors, 2013.

http://www.emersonindustrial.com/en-

en/documentcenter/ControlTechniques/Brochures/unim otor_technical data.pdf. 